\title{
Hoe schaarste tot innovatie leidt
}

\author{
Arjan Munneke
}

\begin{abstract}
Elders in dit nummer beschrijft Rutten de voordelen van toegang tot röntgendiagnostiek op de huisartsenpost [HAP]. ${ }^{1}$ HAP's die toegang hadden tot röntgendiagnostiek, verwezen $40 \%$ van de patiënten met een mogelijke fractuur naar de SEH; voor HAP's zonder die toegang was dat $100 \%$. Prachtige resultaten. Maar wat doe je als radiologie of een radioloog niet op elk uur van de dag beschikbaar is? In Zeeuws-Vlaanderen beoordeelt de dienstdoende huisarts zelf de foto's.
\end{abstract}

Zeeuws-Vlaanderen is een dunbevolkte regio, met een huisartsenpost (HAP) bij het ziekenhuis in Terneuzen. De spoedeisende hulp (SEH) aldaar ontvangt alleen patiënten op verwijzing, dus praktisch alle spoedgevallen komen op de HAP terecht. Specialisten zijn in ANW-uren niet altijd aanwezig, de radioloog ook niet. In het eerste jaar van de huisartsenpost kozen de artsen er daarom vaak voor het röntgenonderzoek uit te stellen tot kantoortijd. Dat jaar kwamen er zo'n vijftig klachten over gemiste fracturen. Er waren creatieve oplossingen nodig om dit aantal terug te dringen. In 2003 besloten de huisartsen en radiologen gezamenlijk tot een innovatie: de huisartsen gingen zelf röntgenfoto's beoordelen. Er werd een röntgenprotocol opgesteld en een radioloog verzorgde een avond 'breukenscholing' voor de huisartsen om hun expertise te vergroten.

\section{HET NIEUWE RÖNTGENPROTOCOL}

De werkwijze sindsdien is als volgt. De dienstdoende huisarts op de HAP verwijst patiënten met een klinisch duidelijke fractuur rechtstreeks naar de SEH; in ANW-uren kan de huisarts bij twijfel röntgenonderzoek van de extremiteiten aanvragen. De röntgenlaborant maakt dan de foto en stuurt deze naar de HAP, waar de huisarts de foto beoordeelt in het kader van het klinische beeld. De patiënt krijgt een brief met informatie over het voorlopige karakter van deze beoordeling en het advies de volgende dag contact op te nemen met de eigen huisarts voor een definitief verslag.

Sinds het protocol in 2003 werd ingevoerd, is het aantal klachten over gemiste fracturen flink gedaald. In januari 2018 is aan vijftig huisartsen in Zeeuws-Vlaanderen een digitale enquête gestuurd over hun ervaringen. Van de 33 respondenten (66\%) maakten er 29 (88\%) regelmatig gebruik van de mogelijkheid om tijdens HAP-uren een röntgenfoto zelf te beoordelen. Te berekenen valt dat de huisartsen in de afgelopen 15 jaar een kleine 7000 röntgenfoto's beoordeeld hebben, waarvan er 20 $(0,28 \%)$ achteraf fout beoordeeld bleken. De radiologen bevestigen dat de fracturen die de dienstdoende arts over het hoofd zag bijna altijd kleine fissuren waren die geen consequenties hadden voor de behandeling op dat moment. Het lijkt er dus

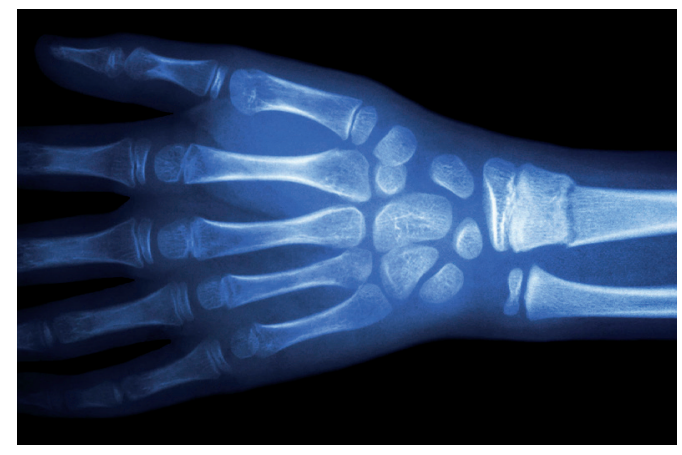

Röntgendiagnostiek op de HAP reduceert het aantal verwijzingen naar de SEH en vergroot de patiënttevredenheid.

Foto: Shutterstock

op dat huisartsen veilig zelf röntgenfoto's van extremiteiten kunnen beoordelen. Van de 33 respondenten wilden er 22 (67\%) doorgaan met deze werkwijze.

\section{BESCHOUWING}

Slechts één op de vijf huisartsenposten in Nederland kan in in eigen beheer radiologisch onderzoek laten uitvoeren. ${ }^{2} \mathrm{Nu}$ is niet alleen gebleken dat röntgendiagnostiek op de HAP het aantal verwijzingen naar de SEH reduceert, maar ook dat het veilig, goedkoop en goed kan worden uitgevoerd door huisartsen en dat het de patiënttevredenheid vergroot - mede vanwege de korte wachttijden.,4

Zoals Rutten stelt, kan röntgendiagnostiek op de HAP de huisarts helpen zijn poortwachterfunctie beter te vervullen. Voordeel van de werkwijze in Zeeuws-Vlaanderen is dat de huisarts de patiënt zelf heeft gezien en de foto kan beoordelen aan de hand van het klinische beeld. Extra scholing is daarvoor aan te raden, ook al hebben de meeste huisartsen tijdens hun klinische stages wel geleerd foto's te beoordelen. Onze enquête was slechts een eerste oriëntatie; verder onderzoek naar de indicaties, het percentage fracturen en het percentage gemiste fracturen is gewenst.

\section{LITERATUUR}

1. Rutten $\mathrm{MH}$, Giesen PH. Toegang tot röntgendiagnostiek op de huisartsenpost. Huisarts Wet 2018;61(6). DOI:10.1007/s12445018-0166-4.

De volledige literatuurlijst staat bij dit artikel op www.henw.org.

Munneke HJ. Hoe schaarste tot innovatie leidt. Huisarts Wet 2018;61[6]:34. DOI: 10.1007/s12445-018-0171-7.

HuisartsenCentrum Zuid, Terneuzen: H.J. Munneke, huisarts, a.munneke@nucleuszorg.nl.

Mogelijke belangenverstrengeling: niets aangegeven. 